\title{
Combination chemoprophylaxis and immunoprophylaxis in reducing the incidence of leprosy
}

This article was published in the following Dove Press journal:

Risk Management and Healthcare Policy

27 April 2016

Number of times this article has been viewed

\author{
Malcolm S Duthie' \\ Marivic F Balagon ${ }^{2}$ \\ 'Infectious Disease Research Institute, \\ Seattle, WA, USA; ${ }^{2}$ Cebu Skin Clinic, \\ Leonard Wood Memorial Center for \\ Leprosy Research, Cebu City, the \\ Philippines
}

\begin{abstract}
Leprosy is a complex infectious disease caused by Mycobacterium leprae that is a leading cause of nontraumatic peripheral neuropathy. Current control strategies, with a goal of early diagnosis and treatment in the form of multidrug therapy, have maintained new case reports at $\sim 225,000$ per year. Diagnostic capabilities are limited and even with revisions to multidrug therapy regimen, treatment can still require up to a year of daily drug intake. Although alternate chemotherapies or adjunct immune therapies that could provide shorter or simpler treatment regimen appear possible, only a limited number of trials have been conducted. More proactive strategies appear necessary in the drive to elimination. As a prevention strategy, most chemoprophylaxis campaigns to date have provided about a 2-year protective window. Vaccination, in the form of a single bacillus Calmette-Guérin (BCG) immunization, generally provides $\sim 50 \%$ reduction in leprosy cases. Adapting control strategies to provide both chemoprophylaxis and immunoprophylaxis has distinct appeal, with chemoprophylaxis theoretically buttressed by vaccination to generate immediate protection that can be sustained in the long term. We also discuss simple assays measuring biomarkers as surrogates for disease development or replacements for invasive, but not particularly sensitive, direct measures of M. leprae infection. Such assays could facilitate the clinical trials required to develop these new chemoprophylaxis, immunoprophylaxis strategies, and transition into wider use.
\end{abstract}

Keywords: mycobacteria, treatment, antibiotics, T-cell, vaccine, prevention Hansen's disease

\section{Epidemiology and etiology of leprosy}

Leprosy, also known as Hansen's disease, is historically associated with disfigurement, social ostracization, and removal of basic human rights. These situations have now thankfully been improved and legally rectified in most countries. Although it is now known that leprosy is a chronic infectious disease caused by Mycobacterium leprae, various myths such as the disease being a divine curse, karma for past misdeeds, or a genetic predisposition, among others, persist. Leprosy can, however, be controlled and is curable.

Leprosy is an extremely complex disease as it manifests across a wide array of symptoms, and various forms can be distinguished and characterized. M. leprae has a predilection for the skin and, uniquely, also the nerves. The World Health Organization (WHO) has established diagnostic criteria as the presence of one or more of the following key signs: appearance of hypopigmented or reddish lesion with hypoesthesia, presence of acid-fast bacilli in lymph node smears, and compatible skin lesion histopathology. Although nonfatal and typically characterized by the appearance of skin lesions, leprosy is one of the most common worldwide causes of nontraumatic 
peripheral neuropathy. Neuropathy arises not only from the infection and damage of peripheral nerves by $M$. leprae itself but also from the inflammatory and immunologic responses to the infection. In addition, as many as half of all patients may be affected by one of the two major clinical types of leprosy reactions, which are acute inflammatory complications that can develop during the course of leprosy irrespective of treatment status. The inflammation associated with reactions can be a medical emergency that often requires hospitalization. If nerve damage is allowed to progress, it can become disabling or, through sensory loss, lead to traumatic injury. ${ }^{1-3}$

Once diagnosed, leprosy is treatable and patients are operationally defined into one of two categories, paucibacillary (PB) and multibacillary (MB), for treatment purposes. The Ridley-Jopling scale characterizes five forms of leprosy through the use of clinical, histopathological, and immunological methods: lepromatous leprosy (LL), borderline lepromatous, mid-borderline, borderline tuberculoid (BT), and tuberculoid leprosy (TT). ${ }^{4,5}$ A pure neural leprosy presentation, which is $\mathrm{PB}$, also exists. PB leprosy patients, encompassing TT and a number of BT forms, are characterized as having one or few skin lesions and granulomatous dermatopathology with low or absent bacterial indices (BI). At the extreme PB pole, TT patients demonstrate a specific cell-mediated immunity against $M$. leprae and have an absent, or low, BI. Control of bacterial growth by PB patients indicates that these individuals mount a strong, but not necessarily curative, immune response against $M$. leprae. MB leprosy encompasses LL, borderline lepromatous, mid-borderline, and a number of BT forms. At the extreme MB pole, LL patients demonstrate high titers of anti-M. leprae antibodies but an absence of specific cell-mediated immunity. ${ }^{4}$ In the absence of a strong cellular immune response, LL patients do not control bacterial replication and have high BI. Because most of the clinicians and health care workers who are seeing patients typically have limited facilities that cannot readily determine Ridley-Jopling classification, the simplified WHO diagnostic criteria have been widely adopted as the preferred diagnostic strategy. Reliance on only one key criterion for the operational MB/PB diagnosis presents limitations; however, because not all lesions are obviously hypopigmented or erythematous, and they are not always anaesthetic. The clinical diagnosis may be supported by the histopathological analysis of a skin lesion, especially when bacilli and/or a neural infiltration are found, but these methods do not have good sensitivity. This is especially true for patients with indeterminate or TT presentations.
Treatment for leprosy has evolved over time. Since 1995, based upon the annual reporting of new cases, WHO has disseminated a cocktail of antibiotics for free of charge in the form of multidrug therapy (MDT). The widespread provision of MDT and revised, shortened treatment regimens have been major contributors to the massive reduction of registered leprosy cases. Although 16 countries reported $>1,000$ new cases during 2009, all but a handful have yet to achieve a prevalence rate of less than one case per 10,000 persons, the threshold considered indicative of eliminating leprosy as a public health problem. ${ }^{6}$ In all WHO regions and at a global level, the number of new cases reported during the reporting year has stabilized in recent years, and continued or renewed vigilance appears necessary. ${ }^{7}$ Leprosy is not evenly spread and localized regions with higher incidence rates can generally be distinguished within most reporting countries. ${ }^{8-11}$ Several Indian states are reporting the maintenance of, or reemergence of prevalence rates to, levels above the national target, and an abundance of new cases are now being detected in the Amazon region of Brazil. ${ }^{12-14}$ Many cases are likely not being diagnosed and the reported numbers probably significantly underrepresent the real leprosy situation. ${ }^{15}$

Interestingly, conditions with which to culture $M$. leprae in vitro have not been determined, and how M. leprae enters the body to establish infection is not definitively known. Many patients anecdotally connect the site of their first obvious lesion with some previous injury or skin break, and entry through the skin is implied. Similarly, it is unclear how transmission occurs, although person-to-person transmission and subsequent expulsion of $M$. leprae directly in the skin and nasal epithelia are strongly suggested. ${ }^{16} \mathrm{MB}$ cases typically have large numbers of acid-fast bacilli deep in the dermis, and although there are reports of $M$. leprae in the desquamating epithelium, there are no reports of acid-fast bacilli being found in the epidermis. It is, therefore, unclear if $M$. leprae reach the skin surface in large enough numbers to represent a meaningful mechanism of transmission. ${ }^{17} \mathrm{LL}$ patients have relatively large amounts of $M$. leprae in the superficial keratin layer of the skin, suggesting that the bacteria may exit along with the sebaceous secretions. ${ }^{18}$ The quantity of $M$. leprae within nasal mucosal lesions of LL patients can be as high as $1 \times 10^{7}$ bacilli, and most lepromatous patients have bacilli that are expelled into their nasal secretions by simply blowing the nose. ${ }^{19-21}$ Research, therefore, increasingly favors the respiratory route as the major mode of expulsion and potential transmission to others. ${ }^{22,23}$ Alongside genetic factors, one of the most significant risk factors for developing leprosy 
is long-term contact, typically through sharing the same residence, with an untreated MB leprosy patient.

\section{Treatment strategies}

In order to develop preventative strategies to reduce the incidence of leprosy, it is instructive to understand how the disease is treated and to consider the current limitations and potential complications that may arise.

\section{Chemotherapy}

Treatments for leprosy have undergone considerable evolution in the past century: from chaulmoogra oil in 1915 to promin, a sulfone drug that successfully treated leprosy but required many painful injections in the 1940s, to dapsone monotherapy in 1946, and then eventually to MDT in 1982 (Figure 1). By the 1960s, resistance to dapsone had started to develop, and dapsone-resistant $M$. leprae strains are now prevalent. In 1981, a WHO study group recommended MDT, a combination of dapsone, rifampicin (RIF), and clofazimine. This cocktail is safe and effective and provided in convenient monthly calendar blister packs. Since 1995, WHO has been providing free MDT for all patients in the world, initially through the drug fund provided by the Nippon Foundation and since 2000, through Novartis and the Novartis Foundation. As part of Novartis's commitment to the 2012 London Declaration on Neglected Tropical Diseases, the company renewed its pledge to work to end leprosy by extending its donation of MDT through 2020. This includes MDT and support costs, to aid WHO with the donation and logistics, worth $>$ US $\$ 40$ million with an overall expectation of reaching an estimated 1.3 million patients.

MDT, consisting of RIF, clofazimine, and dapsone for MB leprosy patients and RIF and dapsone for PB leprosy patients, alters the course of disease in leprosy patients and is the most common way to limit the dissemination of M. leprae to others. Interestingly, RIF is the only component that is strongly bactericidal for M. leprae..$^{24,25}$ Dapsone is a sulfone antibiotic for which anti-inflammatory and immunomodulatory effects have been recognized, but the precise mechanism of action is not known. Clofazimine has a weakly bactericidal action against $M$. leprae. Because clofazimine is an orangecolored iminophenazine dye, it often causes discoloring of the skin. This skin pigmentation gradually resolves, but it may require up to 2 years once the drug is discontinued to return to pretreatment levels, and patients often feel marked and stigmatized by this and withdraw clofazimine from their treatments as a consequence.

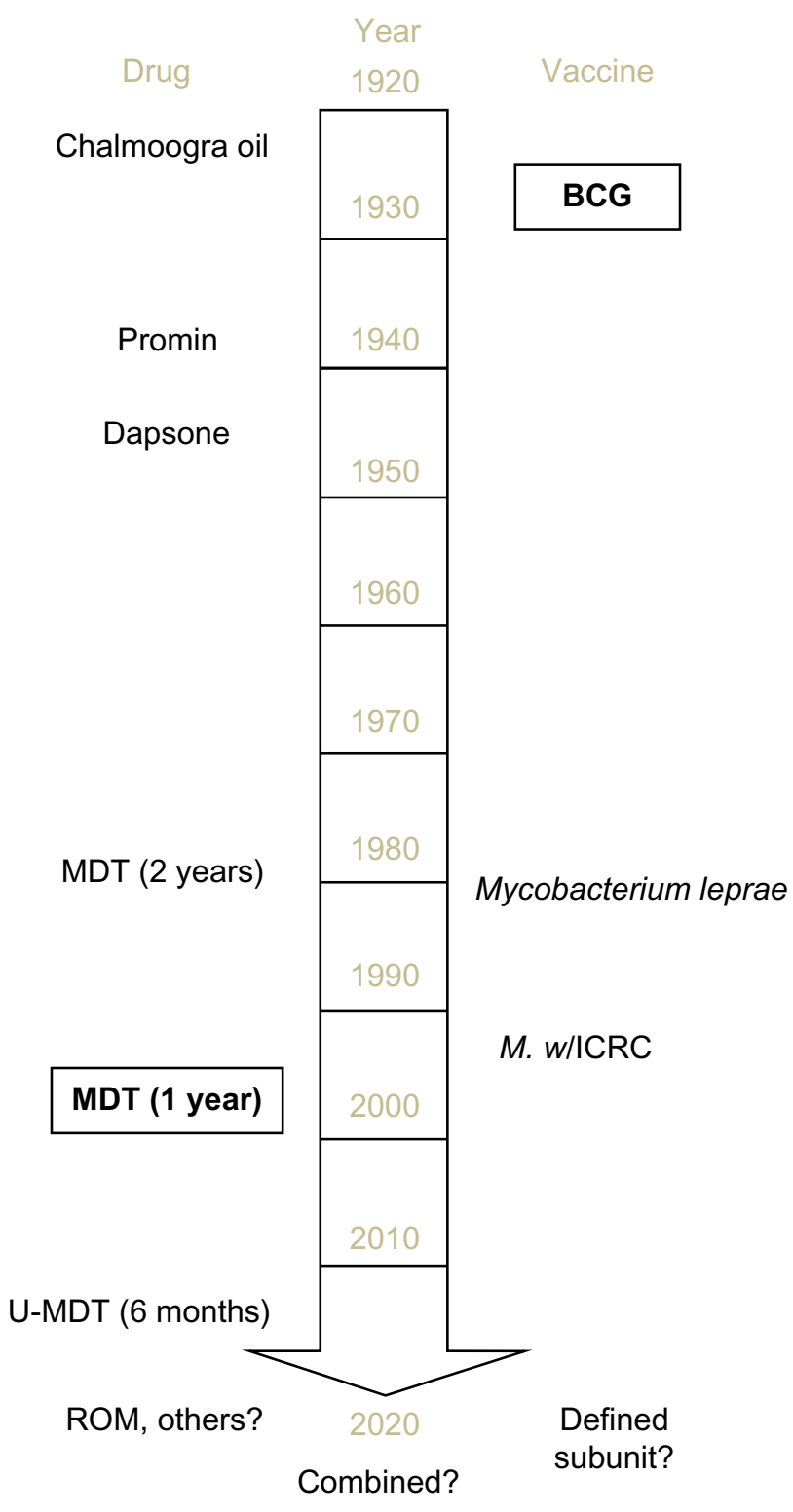

Figure I Timeline of the major treatment and prevention strategies for leprosy. Notes: Drug treatments and preventative vaccine strategies are shown and indicated in the timeframe of the first trial. Current strategies are boxed and shown in bold. Potential new strategies and timelines are indicated at the bottom. Abbreviations: BCG, bacillus Calmette-Guérin; MDT, multidrug therapy; ROM, rifampicin, ofloxacin, and minocycline; U-MDT, uniform multidrug therapy; M. w, Mycobacterium w; ICRC, Indian Cancer Research Center.

Although MDT is effective in the majority of current cases, as mentioned, dapsone resistance is relatively widespread. When combined with clofazimine noncompliance, this means that many patients may unwittingly be taking RIF monotherapy. This has the potential to be highly conducive for the emergence of resistance and several investigators have indeed observed multidrug-resistant strains of M. leprae. ${ }^{26-31}$ The WHO Global Leprosy Programme initiated a Sentinel Surveillance Network to monitor drug resistance in leprosy to proactively monitor the situation..$^{32}$ The widespread 
emergence of drug-resistant $M$. leprae would undermine the efforts of the WHO-MDT campaign. ${ }^{29,33-36}$

Relapse rates after taking MDT are generally low ( $\sim 1 \%)$, but wide variations are reported in different regions and can be unacceptably high in some areas. ${ }^{37,38}$ Relapse rates are dependent on several operational factors. A 10-year prospective study in the Philippines noted a significant difference in the relapse rates of $\mathrm{MB}$ patients followed at a referral center versus those observed in field clinics (9\% and $3 \%$, respectively). ${ }^{39}$ In southern India, a much higher relapse rate, equivalent to 20/1,000 person-years, was observed among MB patients given MDT for 2 years. This rate was reduced to $10 / 1,000$ person-years in patients who were treated until they became smear negative. ${ }^{40}$ In general, higher relapse rates are observed in patients with a high BI at the time of diagnosis, indicating that these patients likely require longer treatment. ${ }^{37,41}$ When relapse does occur, it is often related to poor MDT compliance.

Over time, the duration of leprosy treatments has gradually been shortened: dapsone was given over many years; when first introduced, MDT was administered to MB and PB patients for 2 and 6 months, respectively; since 1998, MDT has been given to MB patients for 1 year. ${ }^{42}$ Even with shortening treatment times, patients can become weary with the length of treatment and may also experience intolerance, side effects, and toxicity from each of the components of the regimen. ${ }^{38,43}$ Despite concerns that a uniform MDT regimen provided to all patients for 6 months may undertreat MB patients, especially those with a high initial BI, and simultaneously overtreat PB leprosy patients, such a regimen has been trialed on the basis that it is operationally more convenient and could therefore be more effective in the context of the integration into general health care services.

While there appears to be a need for alternative bactericidal agents and more combinations that can be used to treat leprosy, these are currently limited. Ofloxacin, as well as other quinolones, has been reported to have a rapid and highly bactericidal activity against $M$. leprae in mouse experiments and human trials. Although moxifloxacin/pefloxacin/ ofloxacin, minocycline, and clarithromycin have all demonstrated greater activity than both dapsone and clofazimine in clinical trials, clinical application of these has been largely confined to the use of single-dose RIF, ofloxacin, and minocycline for single-lesion PB leprosy patients in trials. ${ }^{4-51}$ To evaluate the efficacy of a 4-week ofloxacin-containing regimen for $\mathrm{PB}$ leprosy, we enrolled $\mathrm{PB}$ patients in a randomized, double-blind trial. ${ }^{52}$ One group received the standard 6-month WHO-MDT regimen, whereas the other received
28 daily supervised doses of RIF $600 \mathrm{mg}+$ ofloxacin $400 \mathrm{mg}$, plus 5 months of placebo. Both regimens appeared generally efficacious and resulted in few relapses. While the addition of ofloxacin and minocycline as secondary treatments could attenuate the spread of drug resistance among $M$. leprae, it is noteworthy that ofloxacin resistance has been found in at least two relapses..$^{32,34,44,49,53-56}$ Moxifloxacin, gatifloxacin, and linezolid are all licensed for human use and are used to treat several bacterial infections. PA 824, now called pretomanid, is in an advanced stage of development. Although the efficacy of moxifloxacin, gatifloxacin, linezolid, and PA 824 as antimycobacterials has been demonstrated in tuberculosis (TB) models, these drugs have had only limited amounts of testing in the mouse footpad model of $M$. leprae infection. ${ }^{57,58}$ Evaluations of these agents against replicating $M$. leprae have been undertaken in the mouse footpad model. ${ }^{59}$ A dose-response curve was observed for linezolid activity against $M$. leprae: $25 \mathrm{mg} / \mathrm{kg}$ five times weekly was bacteriostatic, $50 \mathrm{mg} / \mathrm{kg}$ five times weekly was partially bactericidal, and $100 \mathrm{mg} / \mathrm{kg}$ was fully bactericidal. The strong bactericidal activity of moxifloxacin against stationary $M$. leprae was extended by demonstrating activity against "rapidly" multiplying M. leprae. PA 824 was found to lack any activity against rapidly multiplying $M$. leprae. Thus, experimental evaluations of emerging antimycobacterials that are being driven by TB research provide an important transition to inform their potential, or lack thereof, for treating leprosy.

\section{Immunotherapy}

Another strategy with which to reduce the duration of treatment is to adjunct chemotherapy with immune therapy, and the concept of using a vaccine in conjunction with drugs for treatment of leprosy has already been studied. Katoch et al ${ }^{60}$ evaluated untreated high BI cases that were allocated to one of three treatment groups. All patients received a modified MDT regimen; but in addition, one control group received distilled water, another group received bacillus CalmetteGuérin (BCG), and yet another group received killed Mycobacterium w (M. w) every 6 months, until M. leprae was no longer observed in skin slit smears. Despite inducing cell-mediated immunity, the incidence of reactions was not increased by provision of the vaccines. Viable bacteria were detected by outgrowth in mouse footpads in samples from patients on MDT alone up to 24 months of therapy, whereas there was no indication of living $M$. leprae in either of the two immunotherapy groups after 12 months. Patients in both the immunochemotherapy groups showed histological upgrading and accelerated granuloma clearance. 
In a similar study, untreated MB patients with moderate BI were provided MDT for 12 months and one of three treatments (saline, intradermal BCG, or $M . w$, each administered at 3-month intervals for four total doses). ${ }^{61}$ By 12 and 24 months, the patients in BCG group demonstrated a significantly greater improvement in clinical score compared to those in the $M . w$ group, with both the BCG and $M . w$ groups showing reduced clinical scores compared to the MDT only control group. BI declined by 2.40 units per year in patients receiving $\mathrm{BCG}, 2.05$ units per year in the $M . w$ group, and 0.85 units per year in the control group. The incidence of type 2 reactions, neuritis, and development of new deformities was decreased compared to the controls.

These studies indicate that cellular responses can be induced even in leprosy patients with high BI without exacerbating disease and that the addition of immunotherapy to MDT can reduce the effective treatment period required for bacterial clearance.

\section{Preventative strategies}

Although the free, widespread provision of MDT has massively impacted and reduced the global prevalence of leprosy, there are many indications that further effort is required to maintain control and continue onward toward eradication. Active case-finding programs generally record case numbers at rates many fold greater than those detected and reported by the current, passive detection strategies. M. leprae infection does not always cause disease, and estimates are that up to $75 \%$ of infections may be spontaneously cleared without causing significant symptoms. ${ }^{62,63}$ Together, these indicate that reliance on the appearance of clinical symptoms to prompt treatment leaves a large population of $M$. leprae infected individuals with the potential to transmit infection to others who could propagate disease. Focusing on immediate contacts of patients as recruits within trials aiming to reduce the incidence of leprosy is a logical and practical strategy, although large enrollments are still necessary to provide the statistical power required to interpret efficacy.

\section{Chemoprophylaxis}

Various chemoprophylaxis trials have demonstrated a benefit to treating individuals lacking the symptoms of leprosy, especially in those at the highest risk of infection. ${ }^{64-72}$ RIF treatment had a significant impact in Indonesian communities where everybody was given the drug but had no effect in similar communities where only household contacts and direct neighbors were treated. ${ }^{64,73}$ Single-dose RIF treatment showed a protective effect of $57 \%$ in household and other contacts when used as a prophylactic strategy in Bangladesh. ${ }^{74}$ These results are in line with older dapsone prophylaxis programs, which were also found to be more effective when provided to everyone residing in affected communities. ${ }^{70}$ Although generally successful, the relative failure of this approach in a subset of seropositive contacts of MB patients could be that their bacillary load may have been too high to be eliminated by a single dose (or as in Indonesia, two doses) of RIF by the time the chemoprophylaxis is given.

Although each chemoprophylaxis trial has reported a benefit, different magnitudes and the relatively short duration of protection indicate functional limitations. This cannot be entirely unexpected because drugs can only protect those already harboring $M$. leprae, and thus, while chemoprophylactic strategies can reduce the incidence of leprosy in some situations, the nature of drug activity restricts efficacy to a subset of individuals: anyone infected after the chemoprophylaxis is given is not protected. There are also indications that a more extensive regimen may be needed for those nondiseased individuals harboring higher levels of M. leprae.

\section{Vaccines}

By promoting a lasting adaptive immune response, a vaccine, unlike drug treatment, has the potential to provide active and sustained protection. Consistent with exposure or low-level infection, many contacts of leprosy patients exhibit $M$. leprae antigen-specific inflammatory responses and the majority do not develop disease. Thus, the ideal vaccine against leprosy would induce strong, long-lasting T-cell responses directed against $M$. leprae antigens that would limit infection, prevent disease, and, furthermore, reduce bacterial transmission to others.

Although attempts have been made to develop a vaccine based on whole mycobacteria, at present, the $\mathrm{BCG}$ vaccine more typically associated with TB is the only vaccine administered for the prevention of leprosy. The presence of a BCG scar has been recognized as a protective factor for leprosy, but, as clearly indicated by the persistence of leprosy in countries where BCG use is widespread, BCG vaccination does not provide perfect protection against the disease. ${ }^{10}$ The degree of protection afforded by BCG against leprosy has varied dramatically between studies. Systematic meta-analyses indicate that BCG has a wide-ranging protective efficacy with an average $\sim 50 \%$ and protection appears to be better against the MB than the PB form. ${ }^{75,76}$ The use of different BCG strains may be a factor in the varied protection reported across various studies, although this remains unclear. ${ }^{77}$ As with TB, 
the protection afforded by BCG against leprosy is greatest in children and wanes with aging. ${ }^{78-80}$ Computer modeling, based on the 2003 leprosy situation in hyperendemic districts of Bangladesh, indicated that the incidence of leprosy would be substantially reduced by, among various other factors, good BCG vaccine coverage of infants. ${ }^{81}$

Some studies indicate that multiple BCG vaccinations enhance protection and it has been relatively common to recommend the immunization (or reimmunization) of leprosy patients and their contacts. ${ }^{82,83}$ Because no substantial benefit of $\mathrm{BCG}$ revaccination is observed against $\mathrm{TB}$; however, WHO guidelines for TB do not support BCG revaccination. ${ }^{84-86}$ Models including a second BCG vaccination for the prevention of leprosy have not been generated and the efficacy of this approach is debated. ${ }^{75,87-89}$

A major research and development area in the TB field is the refinement of BCG to make it more immunogenic and to provide protection over a longer period. Investigators have genetically refined the bacteria and several recombinant $\mathrm{BCG}$ (rBCG) vaccines are being evaluated. The protection that most of these $\mathrm{rBCG}$ vaccines can afford against leprosy has not been evaluated, and it is therefore unclear what impact they could have on the incidence of leprosy. Only some rBCG vaccines have been produced with consideration of leprosy. ${ }^{90-94}$

M. leprae itself has been assessed in various trials, often to see if it can add to the protective effect of BCG. Largescale human trials were conducted in Venezuela, Malawi, and India to measure the efficacy of BCG with and without killed M. leprae. ${ }^{82,83}$ In Venezuela and Malawi, 5-9 years after vaccination, the incidence rate of all new leprosy cases was reduced across all ages, but the $\mathrm{BCG} / M$. leprae vaccine did not enhance the protection afforded by a primary BCG vaccination alone. Although the observed leprosy incidence rates in a similar trial in South India were not high enough to ascertain the protective efficacy of the vaccines in surveys conducted within the 8 years following immunization, it was determined that BCG/M. leprae improved protection to $64 \%$ whereas BCG alone provided $34.1 \%$ protection. ${ }^{95}$ The reason for this discrepancy is unclear, but it is noteworthy that even if $M$. leprae contributed to protection over BCG, further development of a killed $M$. leprae-containing vaccine would be enormously constrained by the difficulties associated with mass production. Reproducibly generating a consistent product in immune-compromised mice or armadillos would appear to be extremely difficult, if not impossible, although the data do suggest vaccine improvements over BCG are possible.
Several alternate, cultivatable mycobacteria have also been evaluated as leprosy vaccines. In the aforementioned South India trial, one additional group was immunized with the alternative mycobacteria $M . w$, while another group was immunized with Indian Cancer Research Center (ICRC) bacilli. ${ }^{95}$ Both $M . w$ and ICRC bacilli have been demonstrated to protect mice against experimental inoculation of M. leprae. ${ }^{96,97}$ Of all the immunization groups in the South India trial, ICRC bacilli provided the best protection at $65.5 \%$. Despite evaluations indicating that $M . w$ provided the lowest protective efficacy $(25.7 \%)$ of all the vaccines evaluated, a large-scale, double-blind trial of a $M . w$ vaccine in index cases and their household contacts was conducted in Uttar Pradesh, India. ${ }^{98}$ When index cases, and not the contacts, received the M. $w$ vaccine, surveys at 3,6, and 9 years after the initial vaccination indicated protective efficacies of $43 \%, 31 \%$, and $3 \%$, respectively. When only contacts received the vaccine, protective efficacies of $69 \%, 59 \%$, and $39 \%$ were observed. When both patients and contacts received the $M . w$ vaccine, the protective efficacy was $68 \%, 60 \%$, and $28 \%$ at each followup time. Thus, the protective effect of the $M . w$ vaccine in that follow-up trial was sustained for a period of $\sim 7-8$ years. However, $M . w$ has either become widely used in India nor has been evaluated in other leprosy-affected regions.

\section{Combined strategies}

As indicated by combined treatment strategies, the simultaneous provision of chemoprophylaxis and immunoprophylaxis is suggested as an active control strategy with the greatest potential of reducing the incidence of leprosy. Given the live mycobacterial basis of the BCG vaccine, it cannot be administered at the same time as any chemoprophylaxis. A combined strategy involving the staggered provision of RIF and BCG is, however, currently under evaluation. ${ }^{99}$ Unlike BCG, immunization with nonliving vaccines, such as a killed whole mycobacterium or a subunit vaccine, could be provided at the same time as drug treatment. A defined (subunit) vaccine produced by standard methods could negate the quality control concerns associated with whole bacterial vaccines, but such a vaccine is still lacking for leprosy. Experimental immunizations with crude antigens have demonstrated that proteins within the $M$. leprae cell wall, cell membrane, and cytosol all provide protection when administered with an adjuvant before infection. ${ }^{100,101}$ The $35 \mathrm{kDa}$ Ag85B and hsp65 antigens have all been shown to confer protection when expressed in a DNA vaccine. ${ }^{102-104}$ Purified and/or recombinant 10,25 , and $65 \mathrm{kDa}$ proteins have also provided protection in the experimental mouse footpad model. ${ }^{105}$ 
Vaccination of mice with the Ag85 proteins purified from BCG culture filtrate, in conjunction with Freund's incomplete adjuvant, protected by inhibiting $M$. leprae growth. ${ }^{106}$ In a conflicting report, however, recombinant Ag85A/B did not protect when administered with either Freund's incomplete adjuvant or monophosphoryl lipid A. ${ }^{107}$ As with the use of killed M. leprae, the use of crude M. leprae antigens in a vaccine is severely constrained by the need to cultivate large quantities of M. leprae. Selection and production of recombinant antigens have, however, been simplified by the completion and publication of the M. leprae genome in 2001, and a defined subunit vaccine appears within reach. ${ }^{108-110}$

\section{Interpreting protection}

While the primary goal of any intervention is to reduce overall leprosy incidence, slow development of the disease and the relatively low incidence rates (even in leprosy hyperendemic regions) pose logistical problems for statistically powered evaluations. Leprosy incidence rates are typically reported earlier historically reported levels in trials, probably because of both increased awareness of leprosy within the study population and the requirement for closer observance leading to active case finding. ${ }^{11,73,111}$ This, and variance in year-to-year leprosy incidence rates, suggests that experimental trials are better suited to distinguish protective strategies than observational studies. ${ }^{75}$ Observational studies do, however, yield results more quickly. Past studies have either relied on long-term follow-up and comparison of new case detection between untreated and treated groups or on skin slit smears and biopsy to determine how bacterial burden and histological responses of patients have been affected. Surrogate endpoints predictive of response could significantly shorten trials and expedite the adoption of new strategies. The identification of surrogate endpoints indicated by simple biomarkers that could replace, reduce, or negate the need for invasive skin slit or biopsy procedures would also make trials more tractable over larger populations.

The majority of untreated MB leprosy patients can be identified by robust antibody responses at the time of diagnosis and, similar to anti-phenolic glycolipid (PGL)-I IgM responses, IgG responses against protein antigens appear to correlate well with bacterial burden. ${ }^{112-117}$ This suggests that as M. leprae are killed and removed from the body, these responses should diminish. Accordingly, the IgM responses against PGL-I, as well as the IgG responses to the $35 \mathrm{kDa}$ $\mathrm{Ag} 85 \mathrm{~A}$ and $\mathrm{Ag} 85 \mathrm{~B}$ proteins, are all documented to decline during treatment. ${ }^{118-125}$ Decreases during and after MDT in the antibody responses to recombinant protein antigens, including leprosy IDRI diagnostic-1 (LID-1), which is now being used in rapid diagnostic test formats, have also been reported. ${ }^{126-130}$ Significant declines in IgG levels are observed among MB patients after completion of MDT, but declines appear to be less pronounced for anti-PGL-I IgM. ${ }^{126,131,132}$ The rate of decay of anti-PGL-I levels after the initiation of treatment has been reported to range from a linear decline and quick conversion to seronegative through to the retention of positive responses for many years. ${ }^{121,124}$ While it is unclear how antigen-specific antibodies emerge, develop, and retreat in nondiseased individuals, long-term follow-up of serum antibody responses in a large population, such as is desired for vaccine trails, appears entirely feasible.

Interferon- $\gamma($ IFN- $\gamma$ ) release assays are now commonly used for TB and have tended to demonstrate high antigen-specific IFN- $\gamma$ levels at the time of diagnosis that subsequently decline with treatment. We have identified multiple antigens that are recognized in whole blood assays for leprosy patients. ${ }^{115,133}$ It is well documented through the use of whole $M$. leprae or crude antigen fractions that PB patients have strong antigenspecific cellular responses, and this has been corroborated by the observation of IFN- $\gamma$ secretion in whole blood assay (WBA) involving the incubation of untreated PB patient blood with either peptides or recombinant proteins. ${ }^{115,117,134-138}$ Although MB patients are usually considered anergic because they have low or absent cell-mediated immunity to crude fractions of M. leprae, "upgrading" of responses upon vaccination or treatment indicates otherwise. The decreased IFN- $\gamma$ production seen $\sim 2$ years after MDT completion in a recent study of PB patients could possibly be explained by the elimination of bacilli and clearance of antigen from the body. ${ }^{131}$ Indeed, an IFN- $\gamma$ recall response to LID-1 has been observed among MB patients shortly after the conclusion of MDT. ${ }^{131}$ Among the recombinant proteins assessed, this property was unique to LID-1, indicating that the cellular responses of MB patients are antigenically restricted. Why the cellular response against LID-1 emerges in MB leprosy patients after MDT is unclear, but an improved understanding of how successful, and even unsuccessful, treatment affects antigen-specific responses of leprosy patients holds the potential to identify markers that could be used to expedite the introduction of treatments and interventions.

\section{Conclusion}

Leprosy can be treated, and the disfiguring disabilities associated with advanced nerve damage can be prevented. The most effective treatment requires early diagnosis; however, and this requires continued vigilance. In addition, although 
current MDT regimens are highly effective, compliance issues and the potential emergence of drug resistance will continue to be of concern. Although alternate drug or adjunct immune therapies with the potential for use in new, shorter, or simpler treatment regimen appear possible, trials to support their widespread use are limited. As a strategy to reduce the incidence of leprosy, even though estimates show that chemoprophylaxis alone provides a 2 -year protective window, chemoprophylaxis appears as the best currently available strategy. While effective vaccination programs have the potential to provide a more sustained protective window, adapting control strategies to provide both chemoprophylaxis and immunization has distinct appeal and likely provides the greatest opportunity for sustained reductions in the incidence of leprosy. Further research on alternative therapies and new leprosy control strategies need to overcome economic, political, or operational barriers and require advocacy and sponsorship from pertinent stakeholders. Chemoprophylaxis could provide an immediate, short-term protection, with immunization generating a longer-term protection. Simple assays measuring biomarkers as surrogates for disease development or invasive, but not particularly sensitive, direct measures of $M$. leprae infection could facilitate the trials required to transition these new control strategies into wider use.

\section{Acknowledgments}

Leprosy programs under the supervision of the authors have been supported by funding from Leprosy Research Initiative, Philippines Department of Health, Novartis Foundation, Netherlands Leprosy Relief, The Order of Malta, New York Community Trust Heiser Foundation, and American Leprosy Missions.

\section{Disclosure}

The authors report no conflicts of interest in this work.

\section{References}

1. Visschedijk J, van de Broek J, Eggens H, Lever P, van Beers S, Klatser P. Mycobacterium leprae - millennium resistant! Leprosy control on the threshold of a new era. Trop Med Int Health. 2000;5(6): 388-399.

2. Jacob JT, Franco-Paredes C. The stigmatization of leprosy in India and its impact on future approaches to elimination and control. PLoS Negl Trop Dis. 2008;2(1):e113.

3. Cross H. Interventions to address the stigma associated with leprosy: a perspective on the issues. Psychol Health Med. 2006;11(3):367-373.

4. Ridley DS, Jopling WH. Classification of leprosy according to immunity. A five-group system. Int J Lepr Other Mycobact Dis. 1966;34(3): 255-273.

5. Scollard DM. Classification of leprosy: a full color spectrum, or black and white? Int J Lepr Other Mycobact Dis. 2004;72(2):166-168.
6. WHO. Global leprosy situation, 2010. Wkly Epidemiol Rec. 2010; 85(35):337-348.

7. Global leprosy update, 2014: need for early case detection. Wkly Epidemiol Rec. 2015;90(36):461-474.

8. Bakker MI, Hatta M, Kwenang A, et al. Risk factors for developing leprosy - a population-based cohort study in Indonesia. Lepr Rev. 2006;77(1):48-61.

9. Moet FJ, Pahan D, Schuring RP, Oskam L, Richardus JH. Physical distance, genetic relationship, age, and leprosy classification are independent risk factors for leprosy in contacts of patients with leprosy. J Infect Dis. 2006;193(3):346-353.

10. Goulart IM, Bernardes Souza DO, Marques CR, Pimenta VL, Goncalves MA, Goulart LR. Risk and protective factors for leprosy development determined by epidemiological surveillance of household contacts. Clin Vaccine Immunol. 2008;15(1):101-105.

11. Bakker MI, Hatta M, Kwenang A, Klatser PR, Oskam L. Epidemiology of leprosy on five isolated islands in the Flores Sea, Indonesia. Trop Med Int Health. 2002;7(9):780-787.

12. Brook CE, Beauclair R, Ngwenya O, et al. Spatial heterogeneity in projected leprosy trends in India. Parasit Vectors. 2015;8:542.

13. Salgado CG, Ferreira DV, Frade MA, Guimarães Lde S, da Silva MB, Barreto JG. High anti-phenolic glycolipid-I IgM titers and hidden leprosy cases, Amazon region. Emerg Infect Dis. 2012;18(5): 889-890.

14. Barreto JG, Guimaraes Lde S, Frade MA, Rosa PS, Salgado CG. High rates of undiagnosed leprosy and subclinical infection amongst school children in the Amazon Region. Mem Inst Oswaldo Cruz. 2012;107 (Suppl 1):60-67.

15. Smith WC, van Brakel W, Gillis T, Saunderson P, Richardus JH. The missing millions: a threat to the elimination of leprosy. PLoS Negl Trop Dis. 2015;9(4):e0003658.

16. Job CK, Jayakumar J, Kearney M, Gillis TP. Transmission of leprosy: a study of skin and nasal secretions of household contacts of leprosy patients using PCR. Am J Trop Med Hyg. 2008;78(3):518-521.

17. Weddell G, Palmer E. The pathogenesis of leprosy. An experimental approach. Lepr Rev. 1963;34:57-61.

18. Job CK, Jayakumar J, Aschhoff M. "Large numbers" of Mycobacterium leprae are discharged from the intact skin of lepromatous patients; a preliminary report. Int J Lepr Other Mycobact Dis. 1999;67(2):164-167.

19. Shepard CC. Acid-fast bacilli in nasal excretions in leprosy, and results of inoculation of mice. Am J Hyg. 1960;71:147-157.

20. Pedley JC. The nasal mucus in leprosy. Lepr Rev. 1973;44(1):33-35.

21. Naves Mde M, Ribeiro FA, Patrocinio LG, Patrocinio JA, Fleury RN, Goulart IM. Bacterial load in the nose and its correlation to the immune response in leprosy patients. Lepr Rev. 2013;84(1):85-91.

22. Rees RJ, McDougall AC. Airborne infection with Mycobacterium leprae in mice. J Med Microbiol. 1977;10(1):63-68.

23. Araujo S, Lobato J, Reis Ede M, et al. Unveiling healthy carriers and subclinical infections among household contacts of leprosy patients who play potential roles in the disease chain of transmission. Mem Inst Oswaldo Cruz. 2012;107 (Suppl 1):55-59.

24. Shepard CC, Levy L, Fasal P. Rapid bactericidal effect of rifampin on Mycobacterium leprae. Am J Trop Med Hyg. 1972;21(4): 446-449.

25. Shepard CC, Levy L, Fasal P. Further experience with the rapid bactericidal effect of rifampin on Mycobacterium leprae. Am J Trop Med Hyg. 1974;23(6):1120-1124.

26. Grosset JH, Guelpa-Lauras CC, Bobin P, et al. Study of 39 documented relapses of multibacillary leprosy after treatment with rifampin. Int $J$ Lepr Other Mycobact Dis. 1989;57(3):607-614.

27. Williams DL, Gillis TP. Molecular detection of drug resistance in Mycobacterium leprae. Lepr Rev. 2004;75(2):118-130.

28. Matsuoka M, Budiawan T, Aye KS, et al. The frequency of drug resistance mutations in Mycobacterium leprae isolates in untreated and relapsed leprosy patients from Myanmar, Indonesia and the Philippines. Lepr Rev. 2007;78(4):343-352. 
29. Matsuoka M, Kashiwabara Y, Namisato M. A Mycobacterium leprae isolate resistant to dapsone, rifampin, ofloxacin and sparfloxacin. Int J Lepr Other Mycobact Dis. 2000;68(4):452-455.

30. Manjunatha UH, Lahiri R, Randhawa B, Dowd CS, Krahenbuhl JL, Barry CE, 3rd. Mycobacterium leprae is naturally resistant to PA-824. Antimicrob Agents Chemother. 2006;50(10):3350-3354.

31. You EY, Kang TJ, Kim SK, Lee SB, Chae GT. Mutations in genes related to drug resistance in Mycobacterium leprae isolates from leprosy patients in Korea. J Infect. 2005;50(1):6-11.

32. WHO. Meeting on Sentinel Surveillance for Drug Resistance in Leprosy. Geneva: World Health Organization; 2011.

33. Ji B, Jamet P, Sow S, Perani EG, Traore I, Grosset JH. High relapse rate among lepromatous leprosy patients treated with rifampin plus ofloxacin daily for 4 weeks. Antimicrob Agents Chemother. 1997;41(9):1953-1956.

34. Cambau E, Bonnafous P, Perani E, Sougakoff W, Ji B, Jarlier V. Molecular detection of rifampin and ofloxacin resistance for patients who experience relapse of multibacillary leprosy. Clin Infect Dis. 2002;34(1):39-45.

35. Maeda S, Matsuoka M, Nakata N, et al. Multidrug resistant Mycobacterium leprae from patients with leprosy. Antimicrob Agents Chemother. 2001;45(12):3635-3639.

36. Matsuoka M, Kashiwabara Y, Liangfen Z, Goto M, Kitajima S. A second case of multidrug-resistant Mycobacterium leprae isolated from a Japanese patient with relapsed lepromatous leprosy. Int J Lepr Other Mycobact Dis. 2003;71(3):240-243.

37. Gelber RH, Balagon VF, Cellona RV. The relapse rate in MB leprosy patients treated with 2-years of WHO-MDT is not low. Int J Lepr Other Mycobact Dis. 2004;72(4):493-500.

38. Honrado ER, Tallo V, Balis AC, Chan GP, Cho SN. Noncompliance with the world health organization-multidrug therapy among leprosy patients in Cebu, Philippines: its causes and implications on the leprosy control program. Dermatol Clin. 2008;26(2):221-229.

39. Cellona RV, Balagon MF, dela Cruz EC, et al. Long-term efficacy of 2 year WHO multiple drug therapy (MDT) in multibacillary (MB) leprosy patients. Int J Lepr Other Mycobact Dis. 2003;71(4):308-319.

40. Girdhar BK, Girdhar A, Kumar A. Relapses in multibacillary leprosy patients: effect of length of therapy. Lepr Rev. 2000;71(2):144-153.

41. Norman G, Joseph G, Richard J. Relapses in multibacillary patients treated with multi-drug therapy until smear negativity: findings after twenty years. Int J Lepr Other Mycobact Dis. 2004;72(1):1-7.

42. Malathi M, Thappa DM. Fixed-duration therapy in leprosy: limitations and opportunities. Indian J Dermatol. 2013;58(2):93-100.

43. Raju MS, John AS, Kuipers P. What stops people completing multidrug therapy? Ranked perspectives of people with leprosy, their head of family and neighbours - across four Indian states. Lepr Rev. 2015; 86(1):6-20.

44. Ji B, Grosset J. Combination of rifapentine-moxifloxacinminocycline (PMM) for the treatment of leprosy. Lepr Rev. 2000; (Suppl 71):S81-S87.

45. Ji B, Jamet P, Perani EG, et al. Bactericidal activity of single dose of clarithromycin plus minocycline, with or without ofloxacin, against Mycobacterium leprae in patients. Antimicrob Agents Chemother. 1996;40(9):2137-2141.

46. Chan GP, Garcia-Ignacio BY, Chavez VE, et al. Clinical trial of clarithromycin for lepromatous leprosy. Antimicrob Agents Chemother. 1994;38(3):515-517.

47. Costa MB, Cavalcanti Neto PF, Martelli CM, et al. Distinct histopathological patterns in single lesion leprosy patients treated with single dose therapy (ROM) in the Brazilian Multicentric Study. Int J Lepr Other Mycobact Dis. 2001;69(3):177-186.

48. Fajardo TT, Jr., Villahermosa LG, dela Cruz EC, Abalos RM, Franzblau SG, Walsh GP. Minocycline in lepromatous leprosy. Int J Lepr Other Mycobact Dis. 1995;63(1):8-17.

49. Gelber RH, Murray LP, Siu P, Tsang M, Rea TH. Efficacy of minocycline in single dose and at $100 \mathrm{mg}$ twice daily for lepromatous leprosy. Int J Lepr Other Mycobact Dis. 1994;62(4):568-573.
50. Gelber RH, Fukuda K, Byrd S, et al. A clinical trial of minocycline in lepromatous leprosy. BMJ. 1992;304(6819):91-92.

51. Grosset JH, Ji BH, Guelpa-Lauras CC, Perani EG, N'Deli LN. Clinical trial of pefloxacin and ofloxacin in the treatment of lepromatous leprosy. Int J Lepr Other Mycobact Dis. 1990;58(2):281-295.

52. Balagon MF, Cellona RV, Abalos RM, Gelber RH, Saunderson PR. The efficacy of a four-week, ofloxacin-containing regimen compared with standard WHO-MDT in PB leprosy. Lepr Rev. 2010;81(1):27-33.

53. Gelber RH. Chemotherapy of lepromatous leprosy: recent developments and prospects for the future. Eur J Clin Microbiol Infect Dis. 1994;13(11):942-952.

54. Gelber RH, Siu P, Tsang M, Richard V, Chehl SK, Murray LP. Activity of combinations of dapsone, rifampin, minocycline, clarithromycin, and sparfloxacin against $M$. leprae-infected mice. Int J Lepr Other Mycobact Dis. 1995;63(2):259-264.

55. Ji B, Grosset J. Ofloxacin for the treatment of leprosy. Acta Leprol. 1991;7(4):321-326.

56. Ji B, Perani EG, Petinom C, N'Deli L, Grosset JH. Clinical trial of ofloxacin alone and in combination with dapsone plus clofazimine for treatment of lepromatous leprosy. Antimicrob Agents Chemother. 1994;38(4):662-667.

57. Consigny S, Bentoucha A, Bonnafous P, Grosset J, Ji B. Bactericidal activities of HMR 3647, moxifloxacin, and rifapentine against Mycobacterium leprae in mice. Antimicrob Agents Chemother. 2000;44(10):2919-2921.

58. Ji B, Chauffour A, Andries K, Jarlier V. Bactericidal activities of R207910 and other newer antimicrobial agents against Mycobacterium leprae in mice. Antimicrob Agents Chemother. 2006;50(4):1558-1560.

59. Burgos J, de la Cruz E, Paredes R, Andaya CR, Gelber RH. The activity of several newer antimicrobials against logarithmically multiplying $\mathrm{M}$. leprae in mice. Lepr Rev. 2011;82(3):253-258.

60. Katoch K, Katoch VM, Natrajan M, et al. 10-12 years follow-up of highly bacillated BL/LL leprosy patients on combined chemotherapy and immunotherapy. Vaccine. 2004;22(27-28):3649-3657.

61. Narang T, Kaur I, Kumar B, Radotra BD, Dogra S. Comparative evaluation of immunotherapeutic efficacy of BCG and mw vaccines in patients of borderline lepromatous and lepromatous leprosy. Int J Lepr Other Mycobact Dis. 2005;73(2):105-114.

62. Browne SG. Self-healing leprosy: report on 2749 patients. Lepr Rev. 1974;45(2):104-111.

63. Ekambaram V, Sithambaram M. Self-healing in non-lepromatous leprosy in the area of the ELEP Leprosy Control Project Dharmapuri (Tamil Nadu). Lepr India. 1977;49(3):387-392.

64. Bakker MI, Hatta M, Kwenang A, et al. Prevention of leprosy using rifampicin as chemoprophylaxis. Am J Trop Med Hyg. 2005;72(4): 443-448.

65. Smith WC. Chemoprophylaxis in the prevention of leprosy. BMJ. 2008;336(7647):730-731

66. Moet FJ, Oskam L, Faber R, Pahan D, Richardus JH. A study on transmission and a trial of chemoprophylaxis in contacts of leprosy patients: design, methodology and recruitment findings of COLEP. Lepr Rev. 2004;75(4):376-388.

67. Vijayakumaran P, Krishnamurthy P, Rao P, Declerq E. Chemoprophylaxis against leprosy: expectations and methodology of a trial. Lepr Rev. 2000; (Suppl 71):S37-S40; discussion S-1.

68. Nguyen LN, Cartel JL, Grosset JH. Chemoprophylaxis of leprosy in the southern Marquesas with a single $25 \mathrm{mg} / \mathrm{kg}$ dose of rifampicin. Results after 10 years. Lepr Rev. 2000;(Supp1 71):S33-S35; discussion S5-S6.

69. Diletto C, Blanc L, Levy L. Leprosy chemoprophylaxis in Micronesia. Lepr Rev. 2000;(Suppl 71):S21-S33; discussion S4-S5.

70. Smith CM, Smith WC. Chemoprophylaxis is effective in the prevention of leprosy in endemic countries: a systematic review and meta-analysis. MILEP2 Study Group. Mucosal immunology of leprosy. J Infect. 2000;41(2):137-142.

71. Tin K. Population screening and chemoprophylaxis for household contacts of leprosy patients in the Republic of the Marshall Islands. Int J Lepr Other Mycobact Dis. 1999;67(Supp1 4):S26-S29. 
72. Daulako EC. Population screening and mass chemoprophylaxis in Kiribati. Int J Lepr Other Mycobact Dis. 1999;67(4 Suppl):S23-S25.

73. Moet FJ, Schuring RP, Pahan D, Oskam L, Richardus JH. The prevalence of previously undiagnosed leprosy in the general population of northwest Bangladesh. PLoS Negl Trop Dis. 2008;2(2):e198.

74. Moet FJ, Pahan D, Oskam L, Richardus JH; COLEP Study Group. Effectiveness of single dose rifampicin in preventing leprosy in close contacts of patients with newly diagnosed leprosy: cluster randomised controlled trial. BMJ. 2008;336(7647):761-764.

75. Setia MS, Steinmaus C, Ho CS, Rutherford GW. The role of BCG in prevention of leprosy: a meta-analysis. Lancet Infect Dis. 2006;6(3):162-170.

76. Merle CS, Cunha SS, Rodrigues LC. BCG vaccination and leprosy protection: review of current evidence and status of BCG in leprosy control. Expert Rev Vaccines. 2010;9(2):209-222.

77. Behr MA, Wilson MA, Gill WP, et al. Comparative genomics of BCG vaccines by whole-genome DNA microarray. Science. 1999; 284(5419):1520-1523.

78. Zodpey SP, Bansod BS, Shrikhande SN, Maldhure BR, Kulkarni SW. Protective effect of Bacillus Calmette Guerin (BCG) against leprosy: a population-based case-control study in Nagpur, India. Lepr Rev. 1999;70(3):287-294.

79. Zodpey SP, Ambadekar NN, Thakur A. Effectiveness of Bacillus Calmette Guerin (BCG) vaccination in the prevention of leprosy: a population-based case-control study in Yavatmal District, India. Public Health. 2005;119(3):209-216.

80. Rodrigues LC, Kerr-Pontes LR, Frietas MV, Barreto ML. Long lasting BCG protection against leprosy. Vaccine. 2007;25(39-40):6842-6844.

81. Fischer EA, de Vlas SJ, Habbema JD, Richardus JH. The long-term effect of current and new interventions on the new case detection of leprosy: a modeling study. PLoS Negl Trop Dis. 2011;5(9):e1330.

82. Convit J, Sampson C, Zúñiga M, et al. Immunoprophylactic trial with combined Mycobacterium leprae/BCG vaccine against leprosy: preliminary results. Lancet. 1992;339(8791):446-450.

83. KarongaPreventionTrialGroup. Randomised controlled trial of single BCG, repeated BCG, or combined BCG and killed Mycobacterium leprae vaccine for prevention of leprosy and tuberculosis in Malawi. Lancet. 1996;348(9019):17-24.

84. WHO. Global tuberculosis programme and global programme on vaccines. Statement on BCG revaccination for the prevention of tuberculosis. Wkly Epidemiol Rec. 1995;70(32):229-231.

85. Rodrigues LC, Pereira SM, Cunha SS, et al. Effect of BCG revaccination on incidence of tuberculosis in school-aged children in Brazil: the BCG-REVAC cluster-randomised trial. Lancet. 2005;366(9493):1290-1295.

86. Barreto ML, Pereira SM, Ferreira AA. BCG vaccine: efficacy and indications for vaccination and revaccination. J Pediatr (Rio J). 2006; 82(3 Suppl):S45-S54.

87. Düppre NC, Camacho LA, da Cunha SS, et al. Effectiveness of BCG vaccination among leprosy contacts: a cohort study. Trans $R$ Soc Trop Med Hyg. 2008;102(7):631-638.

88. Cunha SS, Alexander N, Barreto ML, et al. BCG revaccination does not protect against leprosy in the Brazilian Amazon: a cluster randomised trial. PLoS Negl Trop Dis. 2008;2(2):e167.

89. van Brakel W, Cross H, Declercq E, et al. Review of leprosy research evidence (2002-2009) and implications for current policy and practice. Lepr Rev. 2010;81(3):228-275.

90. Ohara N, Matsuoka M, Nomaguchi H, Naito M, Yamada T. Inhibition of multiplication of Mycobacterium leprae in mouse foot pads by recombinant Bacillus Catmette-Guérin (BCG). Vaccine. 2000;18(14):1294-1297.

91. Ohara N, Matsuoka M, Nomaguchi H, Naito M, Yamada T. Protective responses against experimental Mycobacterium leprae infection in mice induced by recombinant Bacillus Calmette-Guerin overproducing three putative protective antigen candidates. Vaccine. 2001;19(15-16):1906-1910.
92. Makino M, Maeda Y, Ishii N. Immunostimulatory activity of major membrane protein-II from Mycobacterium leprae. Cell Immunol. 2005;233(1):53-60.

93. Makino M, Maeda Y, Inagaki K. Immunostimulatory activity of recombinant Mycobacterium bovis BCG that secretes major membrane protein II of Mycobacterium leprae. Infect Immun. 2006;74(11):6264-6271.

94. Gillis TP, Tullius MV, Horwitz MA. rBCG30-induced immunity and cross-protection against Mycobacterium leprae challenge are enhanced by boosting with the Mycobacterium tuberculosis 30-kilodalton antigen 85B. Infect Immun. 2014;82(9):3900-3909.

95. Gupte MD, Vallishayee RS, Anantharaman DS, et al. Comparative leprosy vaccine trial in south India. Indian J Lepr. 1998;70(4): 369-388.

96. Sreevatsa, Desikan KV. Evaluation of the efficacy of candidate vaccines against $M$. leprae infection in mice. Indian $J$ Lepr. 1988;60(2):252-259.

97. Bhide MB, Pradhan KS, Bapat CV. A vaccine from ICRC bacilli against $M$. leprae infection in mouse foot-pad. Lepr India. 1978;50(3):334-344.

98. Sharma P, Mukherjee R, Talwar GP, et al. Immunoprophylactic effects of the anti-leprosy $\mathrm{Mw}$ vaccine in household contacts of leprosy patients: clinical field trials with a follow up of 8-10 years. Lepr Rev. 2005;76(2):127-143.

99. Richardus RA, Alam K, Pahan D, Feenstra SG, Geluk A, Richardus JH. The combined effect of chemoprophylaxis with single dose rifampicin and immunoprophylaxis with BCG to prevent leprosy in contacts of newly diagnosed leprosy cases: a cluster randomized controlled trial (MALTALEP study). BMC Infect Dis. 2013;13:456.

100. Gelber RH, Brennan PJ, Hunter SW, et al. Effective vaccination of mice against leprosy bacilli with subunits of Mycobacterium leprae. Infect Immun. 1990;58(3):711-718.

101. Ngamying M, Sawanpanyalert P, Butraporn R, et al. Effect of vaccination with refined components of the organism on infection of mice with Mycobacterium leprae. Infect Immun. 2003;71(3): 1596-1598.

102. Britton WJ, Martin E, Kamath AT, Neupane KD, Roche PW. Immunoprophylaxis against Mycobacterium leprae infection with subunit vaccines. Lepr Rev. 2000;(Suppl 71):S176-S181.

103. Roche PW, Neupane KD, Failbus SS, Kamath A, Britton WJ. Vaccination with DNA of the Mycobacterium tuberculosis 85B antigen protects mouse foot pad against infection with M. leprae. Int J Lepr Other Mycobact Dis. 2001;69(2):93-98.

104. Nomaguchi H, Mukai T, Takeshita F, et al. Effect of hsp65 DNA vaccination carrying immunostimulatory DNA sequences $(\mathrm{CpG}$ motifs) against Mycobacterium leprae multiplication in mice. Int $J$ Lepr Other Mycobact Dis. 2002;70(3):182-190.

105. Gelber RH, Mehra V, Bloom B, et al. Vaccination with pure Mycobacterium leprae proteins inhibits $M$. leprae multiplication in mouse footpads. Infect Immun. 1994;62(10):4250-4255.

106. Naito M, Matsuoka M, Ohara N, Nomaguchi H, Yamada T. The antigen 85 complex vaccine against experimental Mycobacterium leprae infection in mice. Vaccine. 1999;18(9-10):795-798.

107. Ngamying M, Varachit P, Phaknilrat P, Levy L, Brennan PJ, Cho SN. Effects of vaccination with several mycobacterial proteins and lipoproteins on Mycobacterium leprae infection of the mouse. Int J Lepr Other Mycobact Dis. 2001;69(1):43-45.

108. Cole ST, Eiglmeier K, Parkhill J, et al. Massive gene decay in the leprosy bacillus. Nature. 2001;409(6823):1007-1011.

109. Duthie MS, Sampaio LH, Oliveira RM, et al. Development and preclinical assessment of a $73 \mathrm{kD}$ chimeric fusion protein as a defined sub-unit vaccine for leprosy. Vaccine. 2013;31(5):813-819.

110. Duthie MS, Coler RN, Laurance JD, et al. Protection against Mycobacterium leprae infection by the ID83/GLA-SE and ID93/ GLA-SE vaccines developed for tuberculosis. Infect Immun. 2014;82(9):3979-3985. 
111. Schreuder PA, Liben DS, Wahjuni S, Van Den Broek J, De Soldenhoff R. A comparison of Rapid Village Survey and Leprosy Elimination Campaign, detection methods in two districts of East Java, Indonesia, 1997/1998 and 1999/2000. Lepr Rev. 2002;73(4):366-375.

112. Oskam L, Slim E, Bührer-Sékula S. Serology: recent developments, strengths, limitations and prospects: a state of the art overview. Lepr Rev. 2003;74(3):196-205.

113. Reece ST, Ireton G, Mohamath R, et al. ML0405 and ML2331 are antigens of Mycobacterium leprae with potential for diagnosis of leprosy. Clin Vaccine Immunol. 2006;13(3):333-340.

114. Duthie MS, Goto W, Ireton GC, et al. Use of protein antigens for early serological diagnosis of leprosy. Clin Vaccine Immunol. 2007; 14(11):1400-1408.

115. Sampaio LH, Stefani MM, Oliveira RM, et al. Immunologically reactive $M$. leprae antigens with relevance to diagnosis and vaccine development. BMC Infect Dis. 2011;11:26.

116. Hungria EM, de Oliveira RM, de Souza AL, et al. Seroreactivity to new Mycobacterium leprae protein antigens in different leprosy-endemic regions in Brazil. Mem Inst Oswaldo Cruz. 2012;107(Suppl 1): 104-111.

117. Geluk A, Duthie MS, Spencer JS. Postgenomic Mycobacterium leprae antigens for cellular and serological diagnosis of M. leprae exposure, infection and leprosy disease. Lepr Rev. 2011;82(4):402-421.

118. Miller RA, Gorder D, Harnisch JP. Antibodies to phenolic glycolipid-I during long-term therapy: serial measurements in individual patients. Int J Lepr Other Mycobact Dis. 1987;55(4):633-636.

119. Chanteau S, Cartel JL, Celerier P, Plichart R, Desforges S, Roux J. PGL-I antigen and antibody detection in leprosy patients: evolution under chemotherapy. Int J Lepr Other Mycobact Dis. 1989;57(4): 735-743.

120. Meeker HC, Schuller-Levis G, Fusco F, Giardina-Becket MA, Sersen E, Levis WR. Sequential monitoring of leprosy patients with serum antibody levels to phenolic glycolipid-I, a synthetic analog of phenolic glycolipid-I, and mycobacterial lipoarabinomannan. Int $J$ Lepr Other Mycobact Dis. 1990;58(3):503-511.

121. Prakash K, Sehgal VN, Aggarwal R. Evaluation of phenolic glycolipid-I (PGL-I) antibody as a multidrug therapy (MDT) monitor. $J$ Dermatol. 1993;20(1):16-20.

122. Rada E, Ulrich M, Aranzazu N, et al. A follow-up study of multibacillary Hansen's disease patients treated with multidrug therapy (MDT) or MDT + immunotherapy (IMT). Int J Lepr Other Mycobact Dis. 1997;65(3):320-327.

123. Cho SN, Cellona RV, Villahermosa LG, et al. Detection of phenolic glycolipid I of Mycobacterium leprae in sera from leprosy patients before and after start of multidrug therapy. Clin Diagn Lab Immunol. 2001;8(1):138-142.

124. Roche PW, Britton WJ, Failbus SS, Neupane KD, Theuvenet WJ. Serological monitoring of the response to chemotherapy in leprosy patients. Int J Lepr Other Mycobact Dis. 1993;61(1):35-43.
125. Drowart A, Chanteau S, Huygen K, et al. Effects of chemotherapy on antibody levels directed against PGL-I and 85A and 85B protein antigens in lepromatous patients. Int J Lepr Other Mycobact Dis. 1993;61(1):29-34.

126. Duthie MS, Hay MN, Rada EM, et al. Specific IgG antibody responses may be used to monitor leprosy treatment efficacy and as recurrence prognostic markers. Eur J Clin Microbiol Infect Dis. 2011;30(10):1257-1265.

127. Duthie MS, Orcullo FM, Abbelana J, Maghanoy A, Balagon MF. Comparative evaluation of antibody detection tests to facilitate the diagnosis of multibacillary leprosy. Appl Microbiol Biotechnol. 2016;100(7):3267-3275

128. Duthie MS, Raychaudhuri R, Tutterrow YL, et al. A rapid ELISA for the diagnosis of MB leprosy based on complementary detection of antibodies against a novel protein-glycolipid conjugate. Diagn Microbiol Infect Dis. 2014;79(2):233-239.

129. Duthie MS, Balagon MF, Maghanoy A, et al. Rapid quantitative serological test for detection of infection with Mycobacterium leprae, the causative agent of leprosy. J Clin Microbiol. 2014;52(2):613-619.

130. Cardoso LP, Dias RF, Freitas AA, et al. Development of a quantitative rapid diagnostic test for multibacillary leprosy using smart phone technology. BMC Infect Dis. 2013;13(1):497.

131. Freitas AA, Oliveira RM, Hungria EM, et al. Alterations to antigenspecific immune responses before and after multidrug therapy of leprosy. Diagn Microbiol Infect Dis. 2015;83(2):154-161.

132. Rada E, Duthie MS, Reed SG, Aranzazu N, Convit J. Serologic follow-up of IgG responses against recombinant mycobacterial proteins ML0405, ML2331 and LID-1 in a leprosy hyperendemic area of Venezuela. Mem Inst Oswaldo Cruz. 2012;107(Suppl 1):90-94

133. Stefani MM, Guerra JG, Sousa AL, et al. Potential plasma markers of type 1 and type 2 leprosy reactions: a preliminary report. BMC Infect Dis. 2009;9(1):75.

134. Duthie MS, Goto W, Ireton GC, et al. Antigen-specific T-cell responses of leprosy patients. Clin Vaccine Immunol. 2008;15(11):1659-1665.

135. Sampaio LH, Sousa AL, Barcelos MC, Reed SG, Stefani MM, Duthie MS. Evaluation of various cytokines elicited during antigenspecific recall as potential risk indicators for the differential development of leprosy. Eur J Clin Microbiol Infect Dis. 2012;31(7): 1443-1451.

136. Oliveira RM, Hungria EM, de Araújo Freitas A, et al. Synergistic antigen combinations for the development of interferon gamma release assays for paucibacillary leprosy. Eur J Clin Microbiol Infect Dis. 2014;33(8):1415-1424.

137. Geluk A. Biomarkers for leprosy: would you prefer T (cells)? Lepr Rev 2013;84(1):3-12.

138. Bobosha K, Tang ST, van der Ploeg-van Schip JJ, et al. Mycobacterium leprae virulence-associated peptides are indicators of exposure to M. leprae in Brazil, Ethiopia and Nepal. Mem Inst Oswaldo Cruz. 2012;107(Suppl 1):112-123
Risk Management and Healthcare Policy

\section{Publish your work in this journal}

Risk Management and Healthcare Policy is an international, peerreviewed, open access journal focusing on all aspects of public health, policy, and preventative measures to promote good health and improve morbidity and mortality in the population. The journal welcomes submitted papers covering original research, basic science, clinical \& epidemio-

\section{Dovepress}

logical studies, reviews and evaluations, guidelines, expert opinion and commentary, case reports and extended reports. The manuscript management system is completely online and includes a very quick and fair peerreview system, which is all easy to use. Visit http://www.dovepress.com/ testimonials.php to read real quotes from published authors 